\title{
Desmoglein 4 diversity and correlation analysis with coat color in goat
}

\author{
G.X. E1, Y.J. Zhao', Y.H. Ma' ${ }^{2}$, G.L. $\mathrm{Cao}^{3}$, J.N. He${ }^{4}$, R.S. Na', Z.Q. Zhao', \\ C.D. Jiang ${ }^{1}$, J.H. Zhang' ${ }^{1}$, S. Arlvd ${ }^{5}$, L.P. Chen ${ }^{1}$, X.Y. Qiu' ${ }^{1}$, W. Hu ${ }^{1}$ and Y.F. Huang ${ }^{1}$ \\ ${ }^{1}$ Chongqing Key Laboratory of Forage and Herbivore, \\ College of Animal Science and Technology, \\ Chongqing Engineering Research Centre for Herbivores Resource Protection and \\ Utilization, Southwest University, Chongqing, China \\ ${ }^{2}$ Institute of Animal Science, Chinese Academy of Agricultural Sciences, Beijing, \\ China \\ ${ }^{3}$ College of Agriculture, Liaocheng University, Liaocheng, China \\ ${ }^{4}$ College of Animal Science and Technology, Qingdao Agricultural University, \\ Qingdao, China \\ ${ }^{5}$ Department of Psychosomatic Medicine, \\ Inner Mongolia International Mongolian Hospital, Hohhot, China \\ Corresponding author: Y.F. Huang \\ E-mail: H67738337@swu.edu.cn \\ Genet. Mol. Res. 15 (1): gmr.15017814 \\ Received October 9, 2015 \\ Accepted January 18, 2016 \\ Published March 4, 2016 \\ DOI http://dx.doi.org/10.4238/gmr.15017814
}

\begin{abstract}
Desmoglein 4 (DSG4) has an important role in the development of wool traits in domestic animals. The full-length DSG4 gene, which contains $3918 \mathrm{bp}$, a complete open-reading-frame, and encodes a 1040 -amino acid protein, was amplified from Liaoning cashmere goat. The sequence was compared with that of DSG4 from other animals and the results show that the DSG4 coding region is consistent with interspecies conservation. Thirteen single-nucleotide polymorphisms (SNPs) were identified in a highly variable region of $D S G 4$, and one SNP (M-1, G>T) was significantly correlated with white and black coat color in goat. Haplotype distribution of the highly variable region of DSG4 was assessed in 179
\end{abstract}


individuals from seven goat breeds to investigate its association with coat color and its differentiation among populations. However, the lack of a signature result indicates DGS4 haplotypes related with the color of goat coat.

Key words: Desmoglein 4; Diversity; Goat; Evolution; Correlation analysis

\section{INTRODUCTION}

To date, a series of candidate genes have been identified for wool or cashmere traits in domestic animals (Zhou et al., 2011; Geng et al., 2012; Wang et al., 2012). Desmoglein 4 (DSG4) is an example of a candidate gene, whose role in the biological function of coat and skin has been demonstrated in many studies. Green and Jones (1996) found that desmosomes, which are composed of several proteins including desmogleins and desmocollins, mediate cell-cell adhesion in hair follicles. Later, a deletion encompassing exons 5-8 of human DSG4 in families with localized autosomal recessive hypotrichosis ( $\mathrm{LAH}$ ) was found, and a single nucleotide insertion in exon 7 , along with a missense mutation in exon 6 in mice with lanceolate hair (lah) was identified (Kljuic et al., 2003). Subsequently, a number of mutations within DSG4 that are associated with LAH (Messenger et al., 2005; Wajid et al., 2007) and monilethrix hairs in humans (Schaffer et al., 2006; Shimomura et al., 2006; Zlotogorski et al., 2006), and lah in rats (Jahoda et al., 2004; Meyer et al., 2004; Bazzi et al., 2006) were reported, which further indicated the importance of DSG4. In addition, some reports showed that members of the DSG family were associated with skin disease (Amagai, 2010; Amagai and Stanley, 2012). Recent studies have revealed that the DSG4 genotype is strongly associated with wool traits in Chinese indigenous sheep (Zhang et al., 2011a; Ling et al., 2014). These studies strongly suggest that DSG4 is a candidate gene that may contain polymorphic variations affecting wool traits in sheep. However, no study has addressed the complete coding sequence (CDS) region and the wool traits associated with DSG4 in goats.

Therefore, the aim of this investigation was to identify the complete CDS region in DSG4 in Chinese goats, as well as possible polymorphisms within this region and their correlation with coat color. Knowledge of the associations between DSG4 and coat color and the differentiation of this gene among populations will be useful for animal breeding.

\section{MATERIAL AND METHODS}

\section{Sample collection and RNA extraction}

An ovary sample was collected from a Liaoning cashmere goat (Institute of Animal Science, Chinese Agriculture Academy Science, Beijing, China) following the method described by Zhao et al. (2015). The sample was homogenized in TRIzol reagent (Invitrogen, Carlsbad, CA, USA) and total RNA was isolated following the manufacturer protocol.

\section{Primers, amplification, and sequencing of goat DSG4 mRNA}

As shown in Table 1, six pairs of continuous primers (from cDNA-P1 to cDNA-P6) were designed according to the sheep DSG4 sequence (Zhang, 2011), and were synthesized by Shanghai Biological Engineering Technology Services Limited Co. First-strand cDNA was synthesized 
according to the PrimeScript ${ }^{\oplus}$ RT Reagent Kit protocol. The RT-PCR product was stored at $-20^{\circ} \mathrm{C}$. The cDNA was then used as a template for subsequent PCR according to the High Fidelity Taq Enzyme protocol. PCR was performed by mixing $2 \mu \mathrm{L}$ cDNA, $2 \mu \mathrm{L}$ dNTPs (2.5 mM each), $1 \mu \mathrm{L}$ ( 20 pM) each of forward and reverse primers, $0.25 \mu \mathrm{L}(5 \mathrm{U} / \mu \mathrm{L})$ High Fidelity Taq enzyme (TAKARA BIO, Inc., Dalian, China), $5 \mu \mathrm{L}$ 10X PCR buffer ( $\mathrm{Mg}^{2+}$ plus), and $36.75 \mu \mathrm{L}$ sterilized and doubledistilled water in a total 50- $\mu \mathrm{L}$ volume. PCR amplification of the DSG4 gene was performed using an AB Applied Biosystems device (Life-Technologies ${ }^{\mathrm{TM}}$, USA) under the following conditions: $95^{\circ} \mathrm{C}$ for $5 \mathrm{~min}$ (initial denaturation), 30 cycles of at $95^{\circ} \mathrm{C}$ for $30 \mathrm{~s}, 60^{\circ} \mathrm{C}$ for $40 \mathrm{~s}, 72^{\circ} \mathrm{C}$ for $60 \mathrm{~s}, 72^{\circ} \mathrm{C}$ for $10 \mathrm{~min}$, and $4^{\circ} \mathrm{C}$ for $30 \mathrm{~min}$. One-fifth of each PCR product was electrophoresed on a $1.5 \%$ agarose gel, stained with ethidium bromide, and visualized under UV light.

Table 1. Primer sequences, product size, and annealing temperature of RT-PCR.

\begin{tabular}{|c|c|c|c|}
\hline Name & Primer sequence for PCR & Length (bp) & Annealing temperature $\left({ }^{\circ} \mathrm{C}\right)$ \\
\hline \multirow[t]{2}{*}{ cDNA-P1 } & GACCAGGCTCAAATCAAATCTC & \multirow[t]{2}{*}{458} & \multirow[t]{2}{*}{60} \\
\hline & CCTTTCTAAGTCTTCACCCCG & & \\
\hline \multirow[t]{2}{*}{ CDNA-P2 } & CGACCGCCCTATGGAGTGTT & \multirow[t]{2}{*}{1058} & \multirow[t]{2}{*}{60} \\
\hline & ATCTCGCCAGTCCTTGAATCT & & \\
\hline \multirow[t]{2}{*}{ cDNA-P3 } & GTTTCACCACTCGGTTGCTT & \multirow[t]{2}{*}{814} & \multirow[t]{2}{*}{60} \\
\hline & TGAAGCCTCAGTTTGGTCGT & & \\
\hline \multirow[t]{2}{*}{ cDNA-P4 } & CCCCAGGGACAGCGGACA & \multirow[t]{2}{*}{741} & \multirow[t]{2}{*}{60} \\
\hline & TGTCCAGGAAAGCCAGGTT & & \\
\hline \multirow[t]{2}{*}{ cDNA-P5 } & GAGGAGGAACAGTTGAAGGG & \multirow[t]{2}{*}{1006} & \multirow[t]{2}{*}{60} \\
\hline & TATGTTGGTGATTACAAGGTGC & & \\
\hline \multirow[t]{2}{*}{ cDNA-P6 } & ACATCCCCAGTGACCTCTCG & \multirow[t]{2}{*}{1472} & \multirow[t]{2}{*}{60} \\
\hline & GCAAGAAGCACTACAGTTATTT & & \\
\hline
\end{tabular}

The PCR products were extracted using an Agarose Gel DNA Fragment Recovery Kit Ver. 2.0 Protocols (TaKaRa, Dalian, China) and then inserted into pMD18-T Simple Vectors (TaKaRa) according to the manufacturer protocols. Positive plasmids were named pMD18-T-DSG41 and sequenced using two-way sequencing by Tanyibiotech (Beijing, China).

\section{Phylogenetic analysis of the DSG4 nucleotide and amino acid sequence}

The nucleotide and amino acid sequences of Liaoning cashmere goat DSG4 were compared with those published for other species, including Homo sapiens (AAI32908.1), Mus musculus (AAP44999.1), Rattus norvegicus (AAQ88398.1), the DSG4 partial synthetic construct (AIC57789.1), Bos taurus (DAA16012.1; DAA16012.1), H. sapiens (NP 001127925.1; NP 817123.1), Macaca mulatta (XP 001102180.1), Equus caballus (XP 001496441.1), B. taurus (XP 002697734.1), Oryctolagus cuniculus (XP 002713485.1), Callithrix jacchus (XP 002757193.1), Pongo abelii (XP 002828187.1), Ailuropoda melanoleuca (XP 002926714.1), Xenopus (Silurana) tropicalis (XP 002934178.2), Nomascus leucogenys (XP 003262015.1), Sus scrofa (XP 003356443.2), Cavia porcellus (XP 003474064.1), Sarcophilus harrisii (XP 003759868.1), Otolemur garnettii (XP 003784813.1), Pan paniscus (XP 003830305.1; XP 003830306.1), Papio anubis (XP 003914318.1), Saimiri boliviensis boliviensis (XP 003924807.1), Pan troglodytes (XP 
003953318.1), Ovis aries (XP 004020667.1), Gorilla gorilla gorilla (XP 004059331.1), Odobenus rosmarus divergens (XP 004412993.1), Ceratotherium simum simum (XP 004422718.1), Dasypus novemcinctus (XP 004484226.1), Ochotona princeps (XP 004579647.1), Sorex araneus (XP 004606182.1), Octodon degus (XP 004623757.1), Jaculus jaculus (XP 004654908.1), Condylura cristata (XP 004683867.1), Mustela putorius furo (XP 004803803.1), Heterocephalus glaber (XP 004905249.1), Anas platyrhynchos (XP 005009550.1), Mesocricetus auratus (XP 005065408.1), Microtus ochrogaster (XP 005355861.1), Chinchilla lanigera (XP 005373217.1), Macaca fascicularis (XP 005587029.1), Canis lupus familiaris (XP 005623044.1), Capra hircus (KM369171), Myotis brandtii (XP 005857122.1), Bos mutus (XP 005901112.1), Pantholops hodgsonii (XP 005960577.1), Myotis lucifugus (XP 006091735.1), Tupaia chinensis (XP 006150644.1), Camelus ferus (XP 006187223.1), Vicugna pacos (XP 006205143.1), Tarsius syrichta (XP 008071582.1), Eptesicus fuscus (XP 008146584.1), Equus przewalskii (XP 008505115.1), Galeopterus variegatus (XP 008580284.1), Ursus maritimus (XP 008691097.1), and B. taurus (XP 617938.3). The amino acid sequence of DSG4 from Liaoning cashmere goat was aligned with that from other species using the software Clustal $X(1.83)$. Bayesian inference $(\mathrm{BI})$ and maximum likelihood frameworks were used to examine the phylogenetic position of the goat sequence. The best-fitting model (Jones-Taylor-Thornton + Gamma Distributed) of DNA substitution for BI was obtained using jModelTest V. 0.1.1. (Posada, 2008). The neighbor-joining (NJ) phylogenetic tree of DSG4 sequences from these species was constructed using the MEGA (5.0) software (Tamura et al., 2011), and bootstrap values to support the nodes of the tree were based on 100 iterations of the heuristic search. Evolutionary relationships were clarified based on the results of this comparison.

\section{Prediction and analysis of the antigenic domains of goat DSG4}

The main antigenic domains (MADs) of goat DSG4 were predicted with the online tool http://imed.med.ucm.es/Tools/antigenic.pl, using the Jameson-Wolf method (Jameson and Wolf, 1988).

\section{Polymorphism of the high variability region of DSG4}

Blood samples were taken from 179 individuals of seven goat breeds over a large range in southern China, and from one commercial population. The geographic information of these individuals is presented in Table 2 and Figure 1. DNA was extracted using the phenol extraction method. The high variability region of the DSG4 gene was amplified using primers DSG-HV-For (5'-AATGGGGACGTTTTTTGCTTA-3') and DRA-HV-Rev (5'-CTACAACACATAGAGTCGCAGA-3'), which have been previously used in sheep (Zhang, 2011b). PCR amplification was conducted in a PTC-100TM PCR instrument (MJ Research, Inc., USA) in a total reaction volume of $50 \mu \mathrm{L}$ containing 150 ng DNA, $5 \mu \mathrm{L}$ 10X PCR standard reaction buffer, $10 \mathrm{pM}$ dNTPs, $50 \mathrm{mM} \mathrm{MgCl}_{2}, 20 \mathrm{pM}$ each forward and reverse primer, and $2.5 \mathrm{U}$ Taq DNA polymerase from Promega (China). Following an initial denaturation at $95^{\circ} \mathrm{C}$ for $3 \mathrm{~min}, 30$ cycles were performed at $94^{\circ} \mathrm{C}$ for $45 \mathrm{~s}, 60.5^{\circ} \mathrm{C}$ for $45 \mathrm{~s}$, and $72^{\circ} \mathrm{C}$ for $1 \mathrm{~min}$. The final cycle was followed by extension at $72^{\circ} \mathrm{C}$ for $10 \mathrm{~min}$. Tanyibiotech (Beijing, China) performed sequencing by DRA-HV-Rev.

The polymorphism information content (PIC) was estimated from allele frequencies with the Microsatellite toolkit. Screening for haplotypes, the Tajima test, and Fu and Li's F, D, F*, D* test were conducted by DnaSP5.10 (Rozas and Rozas, 1995). Phylogenetic network analyses based on $\mathrm{NJ}$ algorithms were performed to determine the evolutionary relationships and frequency distri- 
bution of the haplotypes using the Networks software (Polzin and Daneshmand, 2003).

Associations between single nucleotide polymorphisms (SNPs) and hair color were assessed by the Fisher exact test (Statistica 8.0, Statsoft Software, Warsaw, Poland) using a generalized linear model and logistic regression analysis. A P value less than 0.05 was considered statistically significant.

Table 2. Information on animals sampled in this study.

\begin{tabular}{l|c|c|l|c|c}
\hline Breeds & Code & Sample size & Sampling location & North latitude & East longitude \\
\hline Dazu black goat & DZ & 27 & Chongqing, China & $29^{\circ} 39^{\prime} 26.25^{\prime \prime}$ & $105^{\circ} 44^{\prime} 14.97^{\prime \prime}$ \\
\hline Hechuan white goat & HW & 17 & Chongqing, China & $29^{\circ} 58^{\prime} 29.98^{\prime \prime}$ & $106^{\circ} 16^{\prime} 21.20^{\prime \prime}$ \\
\hline Youzhou black-skin goat & YU & 38 & Chongqing, China & $28^{\circ} 50^{\prime} 39.76^{\prime \prime}$ & $108^{\circ} 45^{\prime} 48.46^{\prime \prime}$ \\
\hline Inner Mongolia cashmere goat & NM & 19 & Alxa, China & $47^{\circ} 52^{\prime} 6.67^{\prime \prime}$ & $88^{\circ} 56^{\prime} 53.36^{\prime \prime}$ \\
\hline Jianzhou big ear goat & JE & 28 & Chongqing, China & $30^{\circ} 23^{\prime} 22.17^{\prime \prime}$ & $104^{\circ} 31^{\prime} 38.75^{\prime \prime}$ \\
\hline Jining grey goat & JG & 21 & Jining, China & $35^{\circ} 23^{\prime} 48.59^{\prime \prime}$ & $116^{\circ} 35^{\prime} 20.19^{\prime \prime}$ \\
\hline Nubian goat & NB & 29 & Australia & Unknown & \\
\hline
\end{tabular}



Figure 1. Extrinsic features of seven goat. A. Inner Mongolia cashmere goat. B. Hechuan white goat. C. Dazu black goat. D. Jining grey goat. E. Youzhou black-skin goat. F. Jianzhou big ear goat. G. Nubian goat. A and B: pure white coat, C and G: pure black coat, D, E, and F: parti-color coat. 


\section{RESULTS AND DISCUSSION}

Goat (C. hircus) is an important domestic animal worldwide. Coat fiber diameter, length, and color are key traits that contribute to the economic value of the goat; however, these traits are determined by genetic (Bunge et al., 1996; Lamoreux et al., 2001) and environmental (Kidson and Fabian, 1981) factors. To date, many common candidate genetic factors have been found to regulate coat color in other species, including the goat. For example, melanocortin 1 receptor (MC1R) and Agouti Signaling Protein (ASIP) are known to be major regulators of coat color in mice, and MC1R (Våge et al., 1999) and ASIP (Norris and Whan, 2008) are functionally linked to coat color phenotypes in sheep (Gratten et al., 2007; Yang et al., 2013) and yaks (Chen et al., 2009). In addition, tyrosinase-related protein 1 (TYRP1) is a strong candidate gene for coat color variation in Soay sheep (Gratten et al., 2007). Recently, researchers have focused on associations between candidate genes and coat color in goat, such as the red and black coat color phenotypes that are associated with MC1R (Fontanesi et al., 2009) and the brown coat color associated with TYRP1 variants (Becker et al., 2015; Dietrich et al., 2015). However, no single locus has been found to explain all of the divergence in coat color phenotypes. Therefore, there is a multi-locus response with respect to coat color. Recent studies have suggested that DSG4 is responsible for wool and cashmere traits in goat (Zhou et al., 2011; Wang et al., 2012).

In this study, the cDNA sequence of the DSG4 gene from Liaoning cashmere goat including the full-length opening reading frame was obtained after splicing with six sequenced gene fragments of the target gene. The full gene sequence comprises $3120 \mathrm{bp}$ and encodes 1040 amino acids. The molecular weight of the encoded receptor protein is $113.1236 \mathrm{kDa}$, with an isoelectric point of 4.51. We submitted the nucleotide and amino acid sequences of the protein to the GenBank Database (accession No. KM369171).

Evolutionary kinship in the phylogenetic tree (Figure 2) based on the sequence of the open-reading frame of 57 DSG4 isoforms from different animal species, indicates that goat ( $C$. hircus) is most closely related to antelope ( $P$. hodgsonii) and sheep $(O$. aries). This relationship details the evolution of DSG4 among different animal species and interspecies conservation, indicating that DSG4 displays an important and common biological function in different animal species.

The MADs of DSG4 were predicted by Jameson-Wolf methods using the online tool http:// imed.med.ucm.es/Tools/antigenic.pl. The results indicated that 45 MADs lie from the 5th to the 1031th amino acid (Figure 3 and Table S1). These predictions may aid the selection of goat DSG4 antigenic epitopes to enable the preparation of antibodies for use in testing the tissue distribution of DSG4 in vivo.

The highly variable region of the DSG4 gene was amplified and the total length of the aligned sequences was $557 \mathrm{bp}$, including 11 SNPs as follows; M-1: T>C at 86 bp, M-2: G>A at 117 bp, M-3: $A>G$ at 180 bp, M-4: $>>$ G at 205 bp, M-5: $G>A$ at 219 bp, M-6: T>G at 268 bp, M-7: C>T at $319 \mathrm{bp}, \mathrm{M}-8$ : $\mathrm{A}>\mathrm{C}$ at $359 \mathrm{bp}, \mathrm{M}-9: \mathrm{C}>\mathrm{T}$ at $361 \mathrm{bp}, \mathrm{M}-10: \mathrm{C}>\mathrm{T}$ at $455 \mathrm{bp}, \mathrm{M}-11: \mathrm{G}>\mathrm{A}$ at $503 \mathrm{bp}, \mathrm{M}-12$ : $\mathrm{G}>\mathrm{A}$ at $523 \mathrm{bp}$, and M-13: C>T at 529 bp relative to the location of KT596879. Compared with the polymorphism from $\mathrm{PIC}$, high diversity was observed in comparison with other locations among all populations, such as M-1 (0.359) and M-7 (0.261).

Across all individuals, nine haplotypes were constructed by 13 SNPs (Table 3), and their phylogenetic relationship and distribution are shown in Figure 4. All sequences were submitted to GenBank (KT596879-KT596887). The Jianzhou big ear goat (JE) carried more haplotypes (H_2, H_3, H_4, H_8, H_9) than any other breed, which is consistent with its domestic history. According to Animal Genetic Resources in China: Sheep and Goats (China National Commission of Animal Genetic Resources, 2011), JE is a neutral hybrid between the Nubian goat and indigenous breed 
rounding in Southwest China from the Second World War. Two decades ago, these ecotype individuals were consternated, and a specific breed was constructed by artificial breeding for meat production. The genetic material revealed that JE not only shares certain haplotypes $\left(\mathrm{H} \_1, \mathrm{H}\right.$ 2 $)$ with the Nubian goat but also shares a private haplotype $\left(\mathrm{H}_{-} 4\right)$, which is represented in southwest breeds (Dazu black goat and Youzhou black-skin goat). These results suggest that genetic variants of DSG4 may provide molecular evidence and tools for tracing the breeding history of domestic animals.



Figure 2. Phylogenetic tree of the Desmoglein 4 (DSG4) gene. Neighbor-joining phylogenetic tree of DSG4 from different species constructed using the MEGA5 software. Bootstrap values to support the nodes of the tree were based on 100 interactions of the heuristic search. 
AC: (1039 bases)

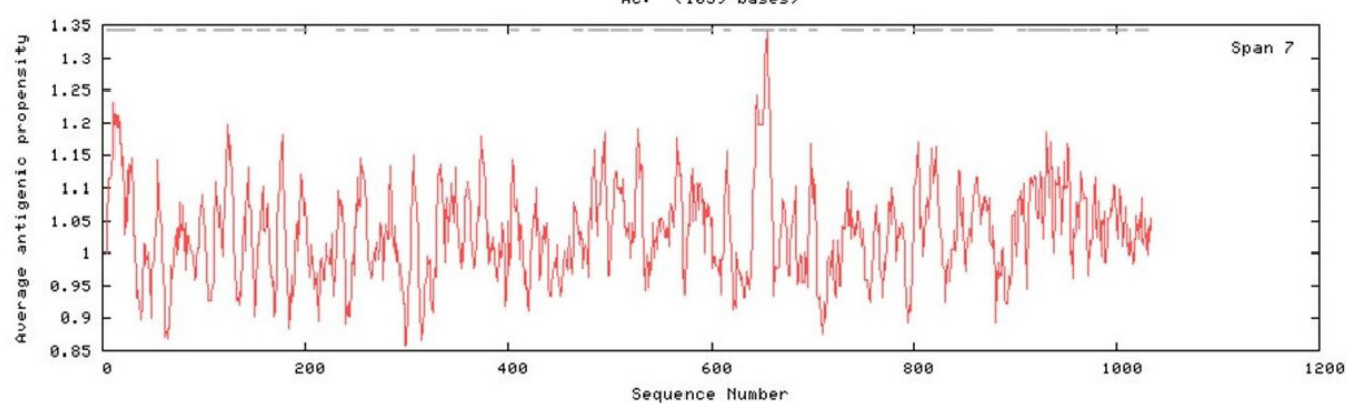

Figure 3. Antigenic domains of DSG4 from Liaoning cashmere goat.

Table 3. Distribution of single-nucleotide polymorphisms (SNPs) in each haplotype.

\begin{tabular}{c|c|c|c|c|c|c|c|c|c|c|c|c|c|c|c}
\hline Hap & M-1 & M-2 & M-3 & M-4 & M-5 & M-6 & M-7 & M-V8 & M-9 & M-10 & M-11 & M-12 & M-13 & FEQ & GN \\
\hline H_1 & T & G & A & A & G & T & C & A & C & C & G & G & C & 186 & KT596879 \\
\hline H_2 & C & G & A & A & G & T & C & A & C & C & G & G & C & 86 & KT596880 \\
\hline H_3 & C & G & A & A & G & T & T & A & C & C & G & G & C & 72 & KT596881 \\
\hline H_4 & T & G & A & A & G & T & T & A & C & C & G & G & C & 5 & KT596882 \\
\hline H_5 & T & G & A & A & A & T & C & A & C & C & G & G & C & 2 & KT596883 \\
\hline H_6 & C & G & A & A & G & T & C & A & C & C & A & G & C & 1 & KT596884 \\
\hline H_7 & C & G & A & A & G & T & C & A & C & T & G & G & C & 2 & KT596885 \\
\hline H_8 & C & A & G & G & G & G & C & C & T & C & G & A & C & 3 & KT596886 \\
\hline H_9 & C & A & G & G & G & G & C & C & T & C & G & A & T & 1 & KT596887 \\
\hline
\end{tabular}

Hap = haplotype; $\mathrm{FEQ}=$ frequency of each haplotype among all individuals; $\mathrm{BN}=$ GenBank accession No.

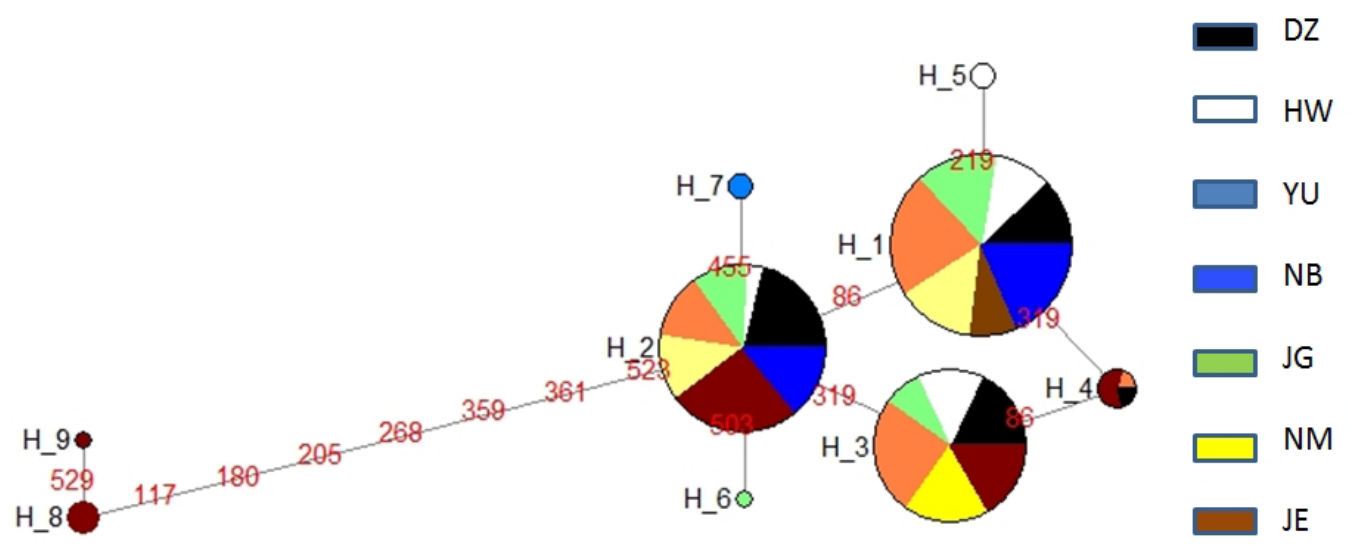

Figure 4. Distribution of haplotype frequencies of the DSG4 highly variable region in each breed.

In addition, the results of the Tajima test and the Fu test are listed in Table 4. Nucleotide diversity, defined as the average number of pairwise nucleotide sequence differences, ranges from 0.00101 (Inner Mongolia cashmere goat) to 0.00328 (Jining grey goat) in this study, indicating a positive signature because of the sweep caused by genetic hitchhiking. In addition, a series of tests, such as Tajima's D and Fu and Li's F, D, $F^{*}, D^{*}$ were performed to assess the deviation from neutrality in each breed. However, the lack of a signature result indicates a pattern of DGS4 haplotypes that deviates from that expected under neutrality. 
Table 4. Summary statistics of the DSG4 highly variable region in goat breeds.

\begin{tabular}{l|c|c|c|c|c|c}
\hline Population & Nucleotide diversity $(\pi)$ & Tajima's D & Fu and Li's D & Fu and Li's F & Fu and Li's D* & Fu and Li's F* \\
\hline DZ & 0.00160 & 1.79859 & 0.73633 & 1.22511 & 0.01370 & -0.51761 \\
\hline HW & 0.00197 & 0.97478 & 0.97343 & 1.14037 & 0.96844 & 1.12121 \\
\hline JG & 0.00171 & -0.12836 & -0.00734 & -0.04553 & 0.08537 & 0.03561 \\
\hline YU & 0.00138 & 1.034844 & 0.72650 & 1.06394 & 0.72938 & 1.06371 \\
\hline NM & 0.00101 & 0.35678 & 0.73633 & 1.22511 & 0.77710 & 0.75923 \\
\hline NB & 0.00158 & 0.71408 & 0.87876 & 0.97048 & 0.87667 & 0.96470 \\
\hline JZ & 0.00328 & -0.45347 & 0.78341 & 0.43129 & 0.76583 & 0.42548 \\
\hline
\end{tabular}

Eleven SNPs with a low frequency variant were not included in the correlation analysis between genotype and coat color. According to the correlation analysis between coat color [black color, white color, hybrid color (parti-color); Figure 1] and M-1, M-7 indicated that there is no significant correlation using the generalized linear model. However, the M-1 location had a highly significant $(P=0.0481)$ correlation with the coat color phenotype. Detailed information regarding the results among white and black individuals using logistic regression analysis is presented in Table 5. Previous reports have shown that the coat color phenotype and its regulating factors are not as simple as expected. Therefore, the identification of a genetic mutation (M-1) in DSG4 may be useful as a potential biomarker for elucidating the genetic mechanism responsible for the development of white and black coats. However, whether the DSG4 variability is responsible for coat color requires further study.

Table 5. Correlation analysis between DSG4 SNPs and coat color phenotype.

\begin{tabular}{c|c|c|c|c|c|c|c|c|c|c|c}
\hline & \multicolumn{3}{|c|}{ Genotype frequency } & \multicolumn{4}{c|}{ Generalized linear model } & \multicolumn{3}{c}{ Logistic regression } \\
\hline Loci & CC & TT & CT & Estimate & Std. Error & t-value & $\operatorname{Pr}>|\mathrm{t}|$ & Estimate & Std. Error & Z-value & Pr $>|\mathrm{z}|$ \\
\hline M-1 & 55 & 71 & 53 & 0.0528 & 0.0792 & 0.6669 & $5.0567 \mathrm{e}^{-01}$ & -0.5301 & 0.2682 & -1.976 & $0.0481^{*}$ \\
\hline $\mathrm{M}-7$ & 130 & 28 & 21 & -0.0390 & 0.0886 & -0.4403 & $6.6024 \mathrm{e}^{-01}$ & 0.2886 & 0.2973 & 0.971 & 0.3316 \\
\hline
\end{tabular}

\section{Conflicts of interest}

The authors report no conflicts of interest.

\section{ACKNOWLEDGMENTS}

Research supported by the Fundamental Research Funds for the Central Universities (\#SWU114023), the National Natural Science Foundation of China (\#31172195), the 2013 Innovation Team Building Program in Chongqing universities (\#KJTD201334), and the Fundamental Research Funds for the Central Universities (\#XDJK2014A010).

\section{REFERENCES}

Amagai M (2010). Autoimmune and infectious skin diseases that target desmogleins. Proc. Jpn. Acad., Ser. B, Phys. Biol. Sci. 86: 524-537. http://dx.doi.org/10.2183/pjab.86.524

Amagai M and Stanley JR (2012). Desmoglein as a target in skin disease and beyond. J. Invest. Dermatol. 132: 776-784. http:// dx.doi.org/10.1038/jid.2011.390

Bazzi H, Getz A, Mahoney MG, Ishida-Yamamoto A, et al. (2006). Desmoglein 4 is expressed in highly differentiated keratinocytes and trichocytes in human epidermis and hair follicle. Differentiation 74: 129-140. http://dx.doi.org/10.1111/ j.1432-0436.2006.00061.x

Becker D, Otto M, Ammann P, Keller I, et al. (2015). The brown coat colour of Coppernecked goats is associated with a nonsynonymous variant at the TYRP1 locus on chromosome 8. Anim. Genet. 46: 50-54. http://dx.doi.org/10.1111/age.12240 
Bunge R, Thomas DL, Nash TG and Lupton CJ (1996). Performance of hair breeds of sheep in Southern Illinois: wool production and fleece quality. J. Anim. Sci. 74: 25-30.

Chen SY, Huang Y, Zhu Q, Fontanesi L, et al. (2009). Sequence characterization of the MC1R gene in yak (Poephagus grunniens) breeds with different coat colors. J. Biomed. Biotechnol. 2009: 861046. http://dx.doi.org/10.1155/2009/861046

China National Commission of Animal Genetic Resources (2011). Animal genetic resources in China: Sheep and goats. Chinese Agricultural Press, Beijing.

Dietrich J, Menzi F, Ammann P, Drögemüller C, et al. (2015). A breeding experiment confirms the dominant mode of inheritance of the brown coat colour associated with the (496) Asp TYRP1 allele in goats. Anim. Genet. 46: 587-588. http://dx.doi. org/10.1111/age.12320

Fontanesi L, Beretti F, Riggio V, Dall'Olio S, et al. (2009). Missense and nonsense mutations in melanocortin 1 receptor (MC1R) gene of different goat breeds: association with red and black coat colour phenotypes but with unexpected evidences. BMC Genet. 10: 47. http://dx.doi.org/10.1186/1471-2156-10-47

Geng RQ, Yuan C and Chen YL (2012). Identification of goat cashmere and sheep wool by PCR-RFLP analysis of mitochondrial 12S rRNA gene. Mitochondrial DNA 23: 466-470. http://dx.doi.org/10.3109/19401736.2012.710206

Gratten J, Beraldi D, Lowder BV, McRae AF, et al. (2007). Compelling evidence that a single nucleotide substitution in TYRP1 is responsible for coat-colour polymorphism in a free-living population of Soay sheep. Proc. Biol. Sci. 274: 619-626. http:// dx.doi.org/10.1098/rspb.2006.3762

Green KJ and Jones JC (1996). Desmosomes and hemidesmosomes: structure and function of molecular components. FASEB J. 10: 871-881.

Jahoda CA, Kljuic A, O'Shaughnessy R, Crossley N, et al. (2004). The lanceolate hair rat phenotype results from a missense mutation in a calcium coordinating site of the desmoglein 4 gene. Genomics 83: 747-756. http://dx.doi.org/10.1016/j. ygeno.2003.11.015

Jameson BA and Wolf $\mathrm{H}$ (1988). The antigenic index: a novel algorithm for predicting antigenic determinants. Comput. Appl. Biosci. 4: 181-186.

Kidson SH and Fabian BC (1981). The effect of temperature on tyrosinase activity in Himalayan mouse skin. J. Exp. Zool. 215: 91-97. http://dx.doi.org/10.1002/jez.1402150111

Kljuic A, Bazzi H, Sundberg JP, Martinez-Mir A, et al. (2003). Desmoglein 4 in hair follicle differentiation and epidermal adhesion: evidence from inherited hypotrichosis and acquired pemphigus vulgaris. Cell 113: 249-260. http://dx.doi. org/10.1016/S0092-8674(03)00273-3

Lamoreux ML, Wakamatsu K and Ito S (2001). Interaction of major coat color gene functions in mice as studied by chemical analysis of eumelanin and pheomelanin. Pigment Cell Res. 14: 23-31. http://dx.doi.org/10.1034/j.16000749.2001.140105.x

Ling $\mathrm{YH}$, Xiang $\mathrm{H}$, Zhang G, Ding JP, et al. (2014). Identification of complete linkage disequilibrium in the DSG4 gene and its association with wool length and crimp in Chinese indigenous sheep. Genet. Mol. Res. 13: 5617-5625. http://dx.doi. org/10.4238/2014.July.25.17

Messenger AG, Bazzi H, Parslew R, Shapiro L, et al. (2005). A missense mutation in the cadherin interaction site of the desmoglein 4 gene underlies localized autosomal recessive hypotrichosis. J. Invest. Dermatol. 125: 1077-1079. http:// dx.doi.org/10.1111/j.0022-202X.2005.23903.x

Meyer B, Bazzi H, Zidek V, Musilova A, et al. (2004). A spontaneous mutation in the desmoglein 4 gene underlies hypotrichosis in a new lanceolate hair rat model. Differentiation 72: 541-547. http://dx.doi.org/10.1111/j.1432-0436.2004.07209007.x

Norris BJ and Whan VA (2008). A gene duplication affecting expression of the ovine ASIP gene is responsible for white and black sheep. Genome Res. 18: 1282-1293. http://dx.doi.org/10.1101/gr.072090.107

Polzin T and Daneshmand SV (2003). On Steiner trees and minimum spanning trees in hypergraphs. Oper. Res. Lett. 31: 1220. http://dx.doi.org/10.1016/S0167-6377(02)00185-2

Posada D (2008). jModelTest: phylogenetic model averaging. Mol. Biol. Evol. 25: 1253-1256. http://dx.doi.org/10.1093/molbev/ $\underline{\mathrm{msn} 083}$

Rozas J and Rozas R (1995). DnaSP, DNA sequence polymorphism: an interactive program for estimating population genetics parameters from DNA sequence data. Comput. Appl. Biosci. 11: 621-625.

Schaffer JV, Bazzi H, Vitebsky A, Witkiewicz A, et al. (2006). Mutations in the desmoglein 4 gene underlie localized autosomal recessive hypotrichosis with monilethrix hairs and congenital scalp erosions. J. Invest. Dermatol. 126: 1286-1291. http:// dx.doi.org/10.1038/sj.jid.5700237

Shimomura Y, Sakamoto F, Kariya N, Matsunaga K, et al. (2006). Mutations in the desmoglein 4 gene are associated with monilethrix-like congenital hypotrichosis. J. Invest. Dermatol. 126: 1281-1285. http://dx.doi.org/10.1038/sj.jid.5700113

Tamura K, Peterson D, Peterson N, Stecher G, et al. (2011). MEGA5: molecular evolutionary genetics analysis using maximum likelihood, evolutionary distance, and maximum parsimony methods. Mol. Biol. Evol. 28: 2731-2739. http://dx.doi. org/10.1093/molbev/msr121 
Våge DI, Klungland H, Lu D and Cone RD (1999). Molecular and pharmacological characterization of dominant black coat color in sheep. Mamm. Genome 10: 39-43. http://dx.doi.org/10.1007/s003359900939

Wajid M, Bazzi H, Rockey J, Lubetkin J, et al. (2007). Localized autosomal recessive hypotrichosis due to a frameshift mutation in the desmoglein 4 gene exhibits extensive phenotypic variability within a Pakistani family. J. Invest. Dermatol. 127: 1779-1782. http://dx.doi.org/10.1038/sj.jid.5700791

Wang X, Zhao ZD, Xu HR, Qu L, et al. (2012). Variation and expression of KAP9.2 gene affecting cashmere trait in goats. Mol. Biol. Rep. 39: 10525-10529. http://dx.doi.org/10.1007/s11033-012-1937-9

Yang GL, Fu DL, Lang X, Wang YT, et al. (2013). Mutations in MC1R gene determine black coat color phenotype in Chinese sheep. ScientificWorldJournal 2013: 675382. http://dx.doi.org/10.1155/2013/675382

Zhang G (2011). Structure, genetic diversity, phylogeny and recombination characteristics of ovine DSG4 gene. Doctorate Thesis, Chinese Academy of Agricultural Sciences. Beijing, China.

Zhang G, Ma YH, Zhang YY, Guan WJ, et al. (2011). Six SNPs and a TTG indel in sheep desmoglein 4 gene are in complete linkage disequilibrium. Afr. J. Biotechnol. 10: 6852-6856.

Zhao ZQ, Wang LJ, Sun XW, Zhang JJ, et al. (2015). Transcriptome analysis of the Capra hircus ovary. PLoS One 10: e0121586. http://dx.doi.org/10.1371/journal.pone.0121586

Zhou JP, Zhu XP, Zhang W, Qin F, et al. (2011). A novel single-nucleotide polymorphism in the $5^{\prime}$ upstream region of the prolactin receptor gene is associated with fiber traits in Liaoning cashmere goats. Genet. Mol. Res. 10: 2511-2516. http:// dx.doi.org/10.4238/2011.October.13.8

Zlotogorski A, Marek D, Horev L, Abu A, et al. (2006). An autosomal recessive form of monilethrix is caused by mutations in DSG4: clinical overlap with localized autosomal recessive hypotrichosis. J. Invest. Dermatol. 126: 1292-1296. http:// dx.doi.org/10.1038/sj.jid.5700251

\section{Supplementary material}

Table S1. The main antigenic domains (MADs) of goat DSG4).

http://www.geneticsmr.com/year2016/vol15-1/pdf/gmr7814 supplementary.pdf 